\title{
Variabilidade da infauna adjacente a estruturas rochosas na plataforma rasa do litoral do Paraná, Brasil
}

\author{
Luciano Lorenzi ${ }^{1} \&$ Carlos A. Borzone ${ }^{2}$
}

\begin{abstract}
1 Laboratório de Bentologia, Unidade São Francisco do Sul, Universidade da Região de Joinville. Caixa Postal 1005, 89240-000 São Francisco do Sul, Santa Catarina, Brasil.E-mail: Ilorenzi@univille.br

${ }^{2}$ Centro de Estudos do Mar, Universidade Federal do Paraná. Caixa Postal 50002, Avenida Beira Mar, Pontal do Sul, 83255-000 Pontal do Paraná, Paraná, Brasil.
\end{abstract}

\begin{abstract}
Variability of the infauna adjacent to rocky formations on the inner continental shelf of Paraná, Brazil. Ocean rocky formations are known as islands. When islands become completely submerged, they are called stone slabs. Like reefs, these formations alter the flux of water produced by the waves, which in turn interacts with the adjacent sediment, altering the sediment and its undulation marks. The alterations caused by the interaction between the waves and emerged or submerged rigid structures can potentially alter the composition and the distributional patterns of the infauna of the adjacent, unconsolidated substrate. In order to evaluate the strength of these alterations, we sampled the infauna and the sediment adjacent to two ocean structures, one emerged and one submerged. Collecting was performed in winter and summer, while discriminating between the faces of the structures, the distances from them, and the troughs and crests of ripple marks. The granulometric characteristics of the sediments and the dimensions of the undulation marks differed in regards to the orientation of and the distance from the structures. Infaunal associations showed differences that can be explained by the sedimentation patterns. However, there were no differences in sediment characteristics and composition of the infauna when troughs and crests were compared. The waves interacted most intensely with the submerged structure, where the sediment showed larger grains next to the undulation marks, what resulted in a more pronounced differentiation of the infauna.
\end{abstract}

KEY WORDS. Infaunal communities; rocky reefs; unconsolidated sediments.

Formações rochosas naturais, que podem aflorar acima do nível do mar formando pequenas ilhas, ou ficarem totalmente submersas, formando lajes ou cabeços, são muito comuns nos litorais sul e sudeste brasileiro. Estas formações são constituídas por rochas cristalinas ígneas pré-cambrianas do embasamento cristalino, principalmente granitos e diques de diabásico de idade juro-cretácea (Angulo \& Araújo 1996). Do ponto de vista geomorfológico, elas se distinguem dos recifes pela sua constituição, sendo estes últimos definidos como agregados de esqueletos de material calcário ou ainda de arenitos cimentados com carbonato de cálcio ou óxido de ferro (Suguio 1992).

Por outro lado, os recifes e as formações rochosas protegem áreas costeiras através da dissipação da energia das ondas e geralmente estão recobertos por organismos vivos e mortos (GARRISON 1996), e afetam de diversas formas as comunidades de organismos infaunais dos fundos inconsolidados que geralmente rodeiam estas estruturas (Posey \& Ambrose 1994). Estas estruturas podem também ser manufaturadas pelo homem, apresentando neste caso uma grande variedade de formas e composições em função da sua finalidade, sendo denominadas de forma geral de recifes artificiais (BAINE 2001).
Em águas costeiras rasas, a interação da topografia com as correntes e ondas predominantes resulta em interações que geram movimentos de rodamoinho seguindo os contornos de ilhas e recifes. Esse efeito pode ser estável e seguir estes contornos, mas também pode ser instável e se dirigir de forma imprevisível ao longo da corrente predominante. O efeito de rastro deixado na água por uma ilha é comum em áreas costeiras rasas onde existe uma homogeneidade na salinidade e na temperatura. Nessas áreas de rastro, o atrito com o fundo gera correntes secundárias que afetam o transporte e a distribuição de sedimento. Nesse sentido, a circulação secundária também pode afetar de forma indireta a distribuição de organismos bentônicos (Wolanski \& Hammer 1988). Em menor escala, as formas de fundo representadas pelas marcas de ondulação podem, através da alternância de cristas e cavas, criar microhabitats com padrões de composição e distribuição de organismos da infauna diferente. Estas marcas, que são determinadas pelo tipo de sedimento e a ação das ondas, também podem se modificar de acordo com a distância a que se encontram de formações rochosas e recifes (BARRos et al. 2004). Todas estas alterações sedimentológicas que surgem através da interação

(c) 2009 Sociedade Brasileira de Zoologia | www.sbzoologia.org.br | All rights reserved. 
física das ondas com a estrutura rígida, seja ela emersa ou submersa, podem influenciar a composição e os padrões de distribuição da infauna do substrato inconsolidado adjacente.

Além das alterações produzidas pela presença física da estrutura, a própria comunidade biológica que nela se desenvolve também pode afetar a infauna adjacente. A produção de compostos orgânicos por algas e outros organismos sésseis disponibiliza alimento para a infauna quando é desprendida pela ação das ondas; por outro lado, a estratégia de busca de alimento exercida por organismos predadores vágeis associados à comunidade do substrato duro pode produzir um halo trófico, ocorrendo a redução da abundância dos organismos do substrato inconsolidado próximo à estrutura (Posey \& AMBrose 1994, Barros et al. 2004).

Apesar da grande diversidade de estudos realizados com comunidades associadas a estruturas rochosas e recifais (BAINE 2001), poucos abordaram as comunidades de substrato inconsolidado adjacente às mesmas. NetTo et al. (1999a) descreveram a composição e os padrões de distribuição da macrofauna e da meiofauna em substratos inconsolidados adjacente ao Atol das Rocas (Brasil). Barros et al. (2001), trabalhando em Botany Bay, Austrália, encontraram uma maior variabilidade nas comunidades da macrofauna bentônica próximas de recifes naturais e artificiais do que nas comunidades que estavam afastadas destas estruturas. Essa variabilidade foi atribuída principalmente às modificações na distribuição do tamanho do grão e ao teor de matéria orgânica do sedimento.

$\mathrm{O}$ presente trabalho teve como objetivo determinar de que forma estruturas rochosas naturais podem influenciar as características da infauna e dos sedimentos nos substratos inconsolidados adjacentes, considerando que esta influência vai ser uma função do distanciamento à estrutura e da orientação às ondas e correntes dominantes. Para isso, foi analisada a composição e os padrões de distribuição da infauna dos substratos inconsolidados adjacentes a duas estruturas rochosas naturais, uma emersa e outra submersa, relacionando estes padrões com as principais características do sedimento e das marcas de ondulação nele formadas.

\section{MATERIAL E MÉTODOS}

No litoral do estado do Paraná encontramos estruturas rochosas na forma de grupos de ilhas intercalados por ambientes de deposição. As ilhas dos Currais $\left(25^{\circ} 44^{\prime} \mathrm{S}, 48^{\circ} 22^{\prime} \mathrm{W}\right)$ formam um arquipélago com três ilhas a aproximadamente seis milhas náuticas do Balneário de Praia de Leste, Município de Pontal do Paraná. A maior ilha que compõe esse arquipélago, com uma área de $59.528 \mathrm{~m}^{2}$, foi escolhida como estrutura emersa e as amostragens ocorreram em $15 \mathrm{~m}$ de profundidade na face exposta às ondas e correntes dominantes (SE) e a $8 \mathrm{~m}$ na face protegida (NW) (Noernberg et al. 2007). Ao sul desse arquipélago, pequenos rochedos acima da linha d'água formam as ilhas Itacolomis $\left(25^{\circ} 50^{\prime} \mathrm{S}, 48^{\circ} 24^{\prime} \mathrm{W}\right)$, com uma área total de
$4.245 \mathrm{~m}^{2}$ e localizadas a aproximadamente oito milhas náuticas do Município de Matinhos, nas proximidades da entrada da Baía de Guaratuba. A aproximadamente $700 \mathrm{~m}$ dessas ilhas encontra-se uma laje rochosa de $50.935 \mathrm{~m}^{2}$, que foi escolhida como estrutura submersa e as amostragens foram realizadas nas profundidades de $15 \mathrm{~m}$ na face exposta (SE) e $17 \mathrm{~m}$ na face protegida (NW) da estrutura (Fig. 1).

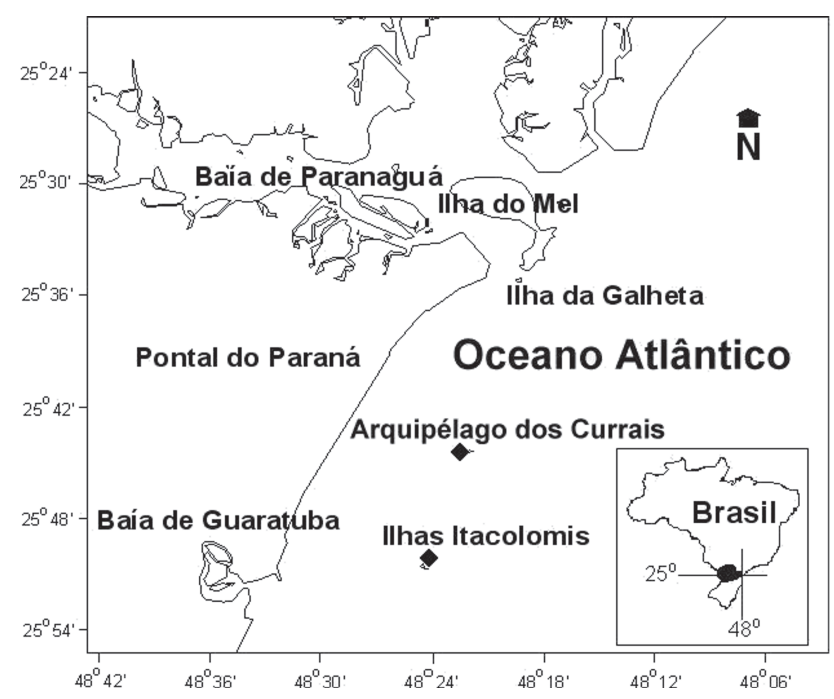

Figura 1. Mapa da localização das estruturas recifais $(\bullet)$ na plataforma rasa do litoral do Paraná.

Nessas duas estruturas foram realizadas amostragens em março (verão) e agosto (inverno) de 2001 através de mergulho autônomo. Na base de cada uma das estruturas foram estabelecidos dois transectos (T1 e T2) separados entre si por $10 \mathrm{~m}$ de distância e perpendiculares à orientação predominante das marcas de ondulação, um par na face exposta e o outro par na face protegida (Fig. 2). Em cada transecto foram estabelecidos dois pontos de coleta, a 1 e a $30 \mathrm{~m}$ de distância da estrutura, coletando-se oito amostras de infauna em cada ponto com um amostrador de $10 \mathrm{~cm}$ de diâmetro por $15 \mathrm{~cm}$ de altura, onde as extremidades foram fechadas com tampas de $10 \mathrm{~cm}$ de diâmetro. Como as marcas de ondulação formaram uma feição comum no sedimento amostrado, foram coletadas quatro réplicas na crista e outras quatro réplicas na cava dessas formações em todos os pontos de coleta. As amostras foram acondicionadas em sacos plásticos e fixadas em formalina 10\% neutralizada. Em cada ponto do transecto foram coletadas duas amostras de 250 g de sedimento, uma na crista e outra na cava das marcas de ondulação. Destas últimas foi medida, com ajuda de uma régua, a distância entre duas cristas, denominada de comprimento de onda. Foram também obtidas a temperatura e a salinidade da água em cada ponto de coleta. 


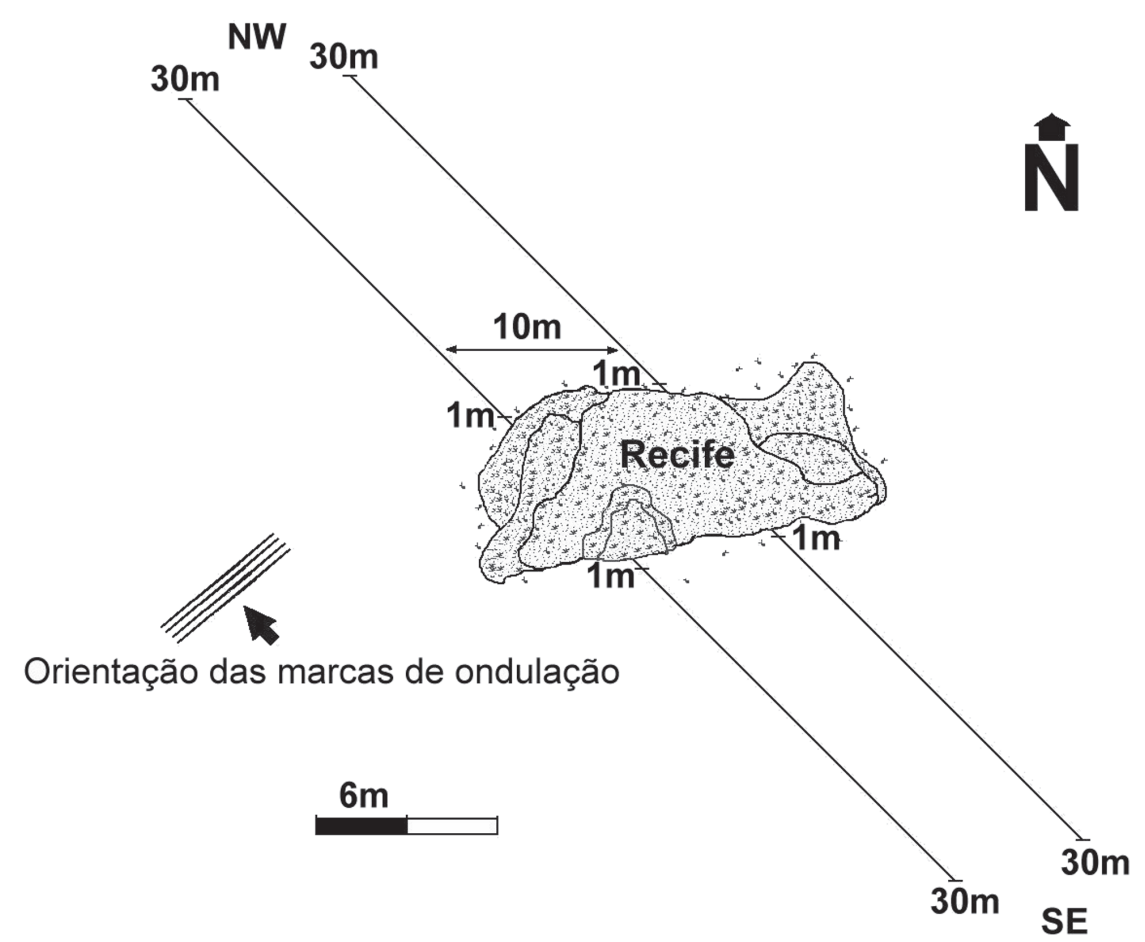

Figura 2. Esquema da amostragem indicando as faces, os transectos e os distanciamentos da estrutura.

Em laboratório a amostra foi peneirada em malha de 500 $1 / 4 \mathrm{~m}$, e os exemplares da infauna retidos foram separados, identificados até o menor nível taxonômico possível e conservados em formalina $10 \%$ neutralizada. Nas amostras de sedimento, a determinação do teor de matéria orgânica e de carbonato biodetrítico foi feita com técnicas de combustão, seguindo o método de DeAn (1974). O teor de finos (silte e argila) foi determinado por pipetagem seguindo Galehouse (1971), e o teor de areia por peneiramento (escala $\phi$ ) (Suguio 1973). Os dados obtidos na granulometria e na pipetagem foram analisados utilizando o método da Medida dos Momentos (TANNER 1995).

Os valores de média, seleção, assimetria, curtose, teor de carbonato de cálcio, teor de matéria orgânica, e o comprimento de onda das marcas de ondulação foram analisados através da Análise de Componentes Principais aplicado numa matriz de covariância. Análises de Correspondência (LEgendre \& Legendre 1998) foram utilizadas para determinar as relações espaciais na distribuição de organismos da infauna e os locais de coleta, utilizando uma matriz feita a partir do somatório das réplicas e dos transectos das densidades dos táxons que foram selecionados em função da frequência relativa (maior ou igual a 1,42\%) e da constância (maior ou igual a 0,17 ). O resultado obtido na análise foi uma representação espacial para cada uma das estruturas (emersa e submersa) e em cada uma das situações (verão e inverno) por separado, discriminando entre amostras coletadas na crista e na cava de cada local de coleta. Finalmente, a comparação entre as duas estruturas, em verão e inverno, foi realizada numa nova Análise de Correspondência utilizando uma matriz onde os dados de crista e cava foram somados.

\section{RESULTADOS}

Os valores de temperatura e salinidade da água de fundo apresentaram diferenças entre as épocas do ano nas duas estruturas, não havendo diferenças entre os pontos para uma mesma coleta. Na ilha dos Currais não houve diferença na salinidade, 35 nas duas coletas, mas a temperatura foi de $23^{\circ} \mathrm{C}$ no verão e $20^{\circ} \mathrm{C}$ no inverno. Já na laje submersa temperatura e salinidade variaram ligeiramente, 23,5 e 35 no verão, e 22 e 33 no inverno.

A análise de componentes principais mostrou padrões diferentes de variação entre as épocas do ano e as estruturas para as características topográficas e granulométricas do substrato adjacente às mesmas. Na estrutura emersa, ilha dos Currais, no verão houve claras diferenças entre as faces, tendo na orientação SE areias grossas a médias $(0,27$ a 1,72 $\phi)$, muito pobremente selecionadas $(1,4$ a $1,6 \phi)$ e com altos teores de carbonato de cálcio (8 a 10\%). Nesta face os comprimentos de onda chegaram a $70 \mathrm{~cm}$ a $30 \mathrm{~m}$ do recife. Já na orientação NW ocorreram areias finas (2,38 a 2,52 ф) com baixos teores de carbonato de cálcio (<3\%) sem grandes diferenças entre as distâncias da estrutura no que se refere aos sedimentos e às marcas de ondulação (Fig. 3). No inverno prevaleceram as diferenças entre as faces, embora o ponto a um metro do recife na face SE apresentou areias finas e menores teores de carbonato e matéria orgânica (Fig. 4). 

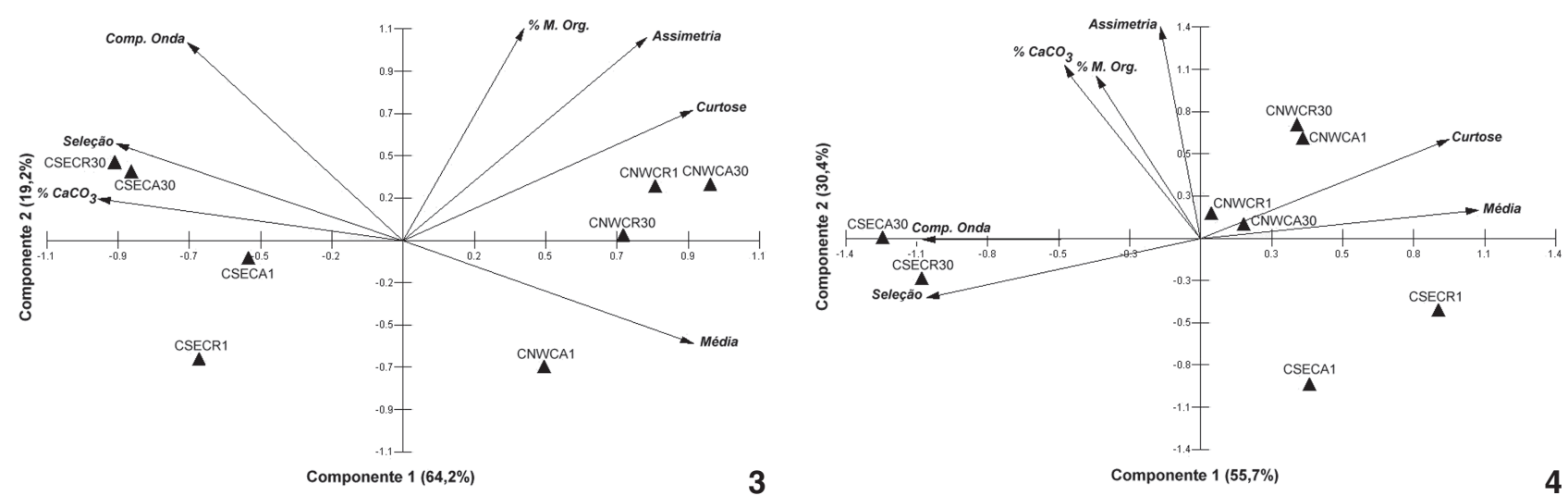

Figuras 3-4. Resultados da análise de Componentes Principais dos parâmetros sedimentológicos da ilha Currais (C) no verão (2) e no inverno (4); na face exposta (SE) e face protegida (NW); nas cristas (CR) e cavas (CA); nos distanciamentos de 1 e $30 \mathrm{~m}$.

Na estrutura submersa um comportamento similar, porém de orientação invertida, foi observado particularmente no ponto distante da face NW. Este ponto apresentou no verão grandes comprimentos de onda $(90 \mathrm{~cm})$ e areias grossas $(0,95 \phi)$ (Fig. 5). Os pontos mais próximos da laje, independente da orientação, ficaram caracterizados por apresentar areias finas $(2,16$ a $2,85 \phi)$, geralmente bem selecionadas $(0,54$ a $1,12 \phi)$ e altos valores de curtose (> $23 \phi)$. No inverno manteve-se o mesmo padrão, mas houve uma maior discriminação entre as faces, sendo que os pontos da face sudeste apresentaram areias muito finas (> $3 \phi$ ) e na face NW, a 1 e $30 \mathrm{~m}$ da estrutura, ocorreram areias média a muito grossa (1,95 a -0,09 $\phi)$ com comprimentos de onda de 17,5 a $35 \mathrm{~cm}$ (Fig. 6), respectivamente. As diferenças granulométricas entre cristas e cavas nunca foram maiores que as diferenças existentes entre orientações e distanciamentos.

Em ambas as estruturas, Polychaeta, Nematoda, Mollusca e Crustacea foram os grupos faunísticos mais representativos quanto ao número de indivíduos e de espécies (Tabs I e II). No entanto, houve algumas diferenças entre as estruturas e os períodos. No verão em Currais os Nematoda representaram 52\% dos indivíduos, enquanto o mesmo valor foi apresentado pelos Polychaeta no inverno. Já na laje submersa os Polychaeta dominaram com $47 \%$ dos indivíduos no verão, e os Nematoda e os Mollusca foram os mais numerosos no inverno (Tab. I). Ambas as estruturas apresentaram menores abundâncias totais no verão, sendo mais do dobro as abundâncias achadas na estrutura emersa.

Quanto à riqueza específica, o grupo com maior número de espécies foi Polychaeta, seguido de Crustacea, Mollusca e Nematoda. O verão quando comparado com o inverno nas duas estruturas, e a estrutura emersa quando comparada com a estrutura submersa nas duas estações, apresentaram riquezas ligeiramente superiores (Tab. II).

Em todas as estruturas e nas duas estações foram particularmente abundantes os poliquetas Hemipodia californiensis
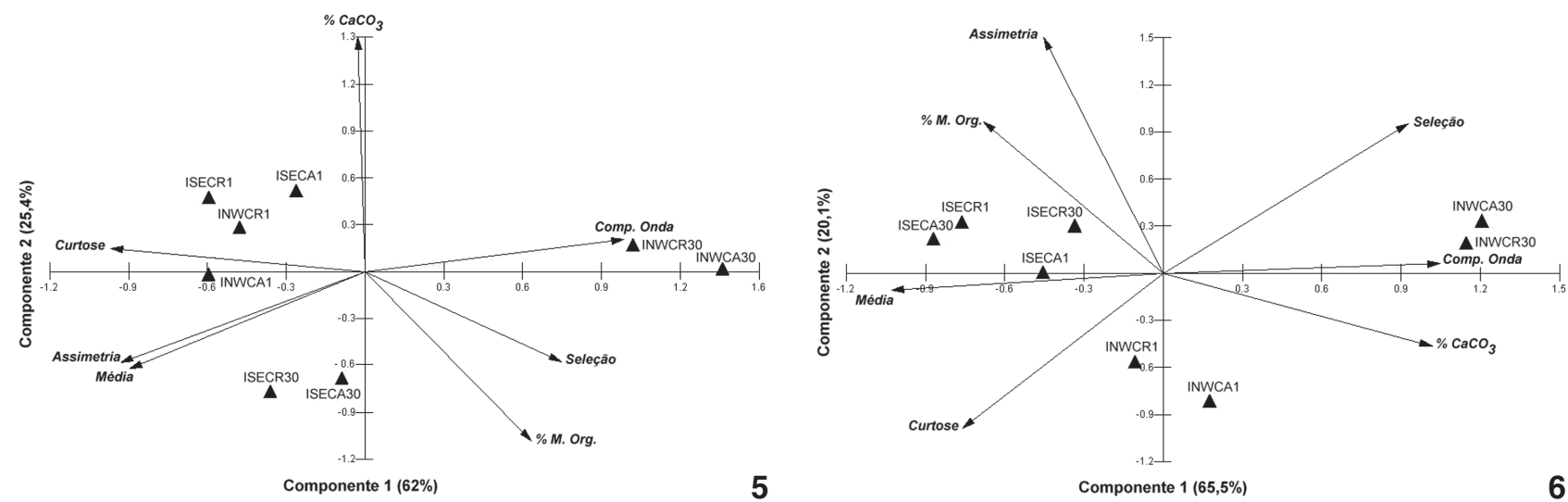

Figuras 5-6. Resultados da análise de Componentes Principais dos parâmetros sedimentológicos da laje submersa nas proximidades das ilhas Itacolomis (I) no verão (5) e no inverno (6); na face exposta (SE) e face protegida (NW); nas cristas (CR) e cavas (CA); nos distanciamentos de 1 e $30 \mathrm{~m}$. 
Tabela I. Número de indivíduos por grupos zoológicos e as respectivas freqüências relativas entre parênteses nas estruturas emersa (ilha Currais) e submersa (laje) no verão e no inverno, e os valores totais de cada grupo.

\begin{tabular}{|c|c|c|c|c|c|}
\hline \multirow{2}{*}{ Grupos } & \multicolumn{2}{|c|}{ Emersa } & \multicolumn{2}{|c|}{ Submersa } & \multirow{2}{*}{ Total } \\
\hline & Verão & Inverno & Verão & Inverno & \\
\hline Polychaeta & $1752(35,1)$ & $2681(51)$ & $866(47,4)$ & $764(29,8)$ & $6063(41,4)$ \\
\hline Nematoda & $2619(52,5)$ & $1850(35,5)$ & $651(35,6)$ & $521(20,3)$ & $5641(38,5)$ \\
\hline Mollusca & $221(4,4)$ & $84(1,6)$ & $71(3,9)$ & $766(29,9)$ & $1142(7,8)$ \\
\hline Crustacea & $126(2,5)$ & $377(7,2)$ & $151(8,3)$ & $222(8,7)$ & $876(6)$ \\
\hline Oligochaeta & $104(2,1)$ & $108(2,1)$ & $7(0,4)$ & $210(8,2)$ & $429(2,9)$ \\
\hline Sipuncula & $76(1,5)$ & $95(1,8)$ & $43(2,4)$ & $68(2,7)$ & $282(1,9)$ \\
\hline Protochordata & $62(1,2)$ & $31(0,6)$ & $27(1,5)$ & $7(0,3)$ & $127(0,9)$ \\
\hline Priapulida & $20(0,4)$ & $0(0)$ & $0(0)$ & $0(0)$ & $20(0,1)$ \\
\hline Platyhelminthes & $2(0,04)$ & $10(0,19)$ & $0(0)$ & $3(0,12)$ & $15(0,1)$ \\
\hline Echinodermata & $1(0,02)$ & $7(0,13)$ & $6(0,3)$ & $0(0)$ & $14(0,1)$ \\
\hline Hidrozoa & $5(0,1)$ & $8(0,15)$ & $0(0)$ & $0(0)$ & $13(0,1)$ \\
\hline Nemertinea & $2(0,04)$ & $5(0,1)$ & $4(0,2)$ & $0(0)$ & $11(0,1)$ \\
\hline Pycnogonida & $0(0)$ & $3(0,06)$ & $0(0)$ & $4(0,16)$ & $7(0,05)$ \\
\hline Lofoforado & $0(0)$ & $0(0)$ & $1(0,05)$ & $0(0)$ & $1(0,01)$ \\
\hline Total & 4990 & 5259 & 1827 & 2565 & 14641 \\
\hline
\end{tabular}

Tabela II. Número de espécies por grupos zoológicos e as respectivas freqüências relativas entre parênteses nas estruturas emersa (ilha Currais) e submersa (laje) no verão e no inverno.

\begin{tabular}{|c|c|c|c|c|}
\hline \multirow{2}{*}{ Grupos } & \multicolumn{2}{|c|}{ Emersa } & \multicolumn{2}{|c|}{ Submersa } \\
\hline & Verão & Inverno & Verão & Inverno \\
\hline Polychaeta & $63(52,9)$ & $54(49,5)$ & $54(51,4)$ & $48(53,3)$ \\
\hline Crustacea & $19(16)$ & $18(16,5)$ & $18(17,1)$ & $18(20)$ \\
\hline Mollusca & $15(12,6)$ & $14(12,8)$ & $12(11,4)$ & $8(8,9)$ \\
\hline Nematoda & $12(10,1)$ & $11(10,1)$ & $10(9,5)$ & $9(10)$ \\
\hline Oligochaeta & $2(1,7)$ & $2(1,8)$ & $2(1,9)$ & $2(2,2)$ \\
\hline Sipuncula & $2(1,7)$ & $2(1,8)$ & $2(1,9)$ & $2(2,2)$ \\
\hline Protochordata & $1(0,8)$ & $1(0,9)$ & $1(1)$ & $1(1,1)$ \\
\hline Priapulida & $1(0,8)$ & $0(0)$ & $0(0)$ & $0(0)$ \\
\hline Platyhelminthes & $1(0,8)$ & $1(0,9)$ & $0(0)$ & $1(1,1)$ \\
\hline Echinodermata & $1(0,8)$ & $3(2,8)$ & $4(3,8)$ & $0(0)$ \\
\hline Hidrozoa & $1(0,8)$ & $1(0,9)$ & $0(0)$ & $0(0)$ \\
\hline Nemertinea & $1(0,8)$ & $1(0,9)$ & $1(1)$ & $0(0)$ \\
\hline Pycnogonida & $0(0)$ & $1(0,9)$ & $0(0)$ & $1(1,1)$ \\
\hline Lofoforado & $0(0)$ & $0(0)$ & $1(1)$ & $0(0)$ \\
\hline Total & 119 & 105 & 109 & 90 \\
\hline
\end{tabular}


(Hartman, 1938) e Exogone arenosa Perkins, 1981, os nematóides Viscosia sp., Pomponema sp., Catanema sp., Epacanthion sp. e Paramesochium sp., e o gastrópode Halistylus sp. O resultado da Análise de Correspondência da infauna da ilha Currais no verão (Fig. 7) mostrou um padrão semelhante ao seguido pelo sedimento, com uma clara diferenciação entre as faces. A face NW formou um grupo único caracterizado pelo bivalve Ervilia concentrica (Holmes, 1860), o poliqueta Paraonis sp. e o nematóide Viscosia sp. Já na face exposta da ilha, cristas e cavas a 1 metro da estrutura apresentaram fortes similaridades pela ocorrência dos poliquetas Paraprionospio sp., Typosyllis sp., sendo que cristas e cavas a $30 \mathrm{~m}$ desta mesma face foram caracterizadas pelos poliquetas E. arenosa, Nothria sp. e Psione sp. Não houve grandes modificações na ordenação apresentada por esta estrutura no inverno, exceto pelo aparecimento do cumáceo Leptocuma borzonei Roccatagliata, 1997 e uma espécie não identificada de anfípode da família Pardaliscidae que contribuíram para a maior discriminação da estação próxima à estrutura do lado exposto da ilha (Fig. 8).

Na estrutura submersa, os padrões de distribuição das espécies e similaridades entre pontos de coleta foram distintos aos achados na estrutura emersa. Tanto no verão como no inverno, as maiores similaridades foram apresentadas pelos pontos correspondentes à face SE, com o poliqueta Prionospio sp., acompanhado do isópode Apseudomorpha no verão, e do cumáceo $L$. borzonei junto com Paraonis sp. no inverno (Figs 9 e 10). Já na face noroeste houve diferenças entre os distanciamentos, com as espécies Phoxocephalopsis zimmeri Schellenberg, 1931, Microspio pigmentata (Reish, 1959) uma espécie de Oligochaeta da família Enchitraeidae caracterizando os locais próximos da estrutura, e as espécies Lumbrinerides gesae Orenzanz, 1973 e o cumáceo Diastylis planifrons Calman 1912, entre outras espécies, caracterizando as amostras a $30 \mathrm{~m}$.

Repetindo os resultados achados para as características sedimentológicas, não houve maiores diferenças na composição da infauna entre cristas e cavas. Desta forma, a análise conjunta das duas estruturas, onde os dados de cristas e cavas foram somados, mostrou que tanto no inverno quanto no verão as estruturas apresentaram composições da infauna diferentes. Esta diferença foi muito acentuada na estrutura submersa, onde os pontos da face exposta mostraram similaridades entre distanciamentos, ao contrário dos pontos da face protegida (Fig. 11). Já em Currais houve uma menor discriminação entre pontos em decorrência de uma maior similaridade faunística quando comparada com a laje submersa.

\section{DISCUSSÃO}

Os sedimentos adjacentes às estruturas rochosas marinhas foram caracterizados pela presença de elevadas proporções de areia fina com baixos teores de matéria orgânica. Este tipo de sedimento domina nos fundos entre 20 e $50 \mathrm{~m}$ de profundidade das áreas próximas aos recifes estudados (Borzone et al. 1999). A variação do sedimento entre as faces exposta e pro-
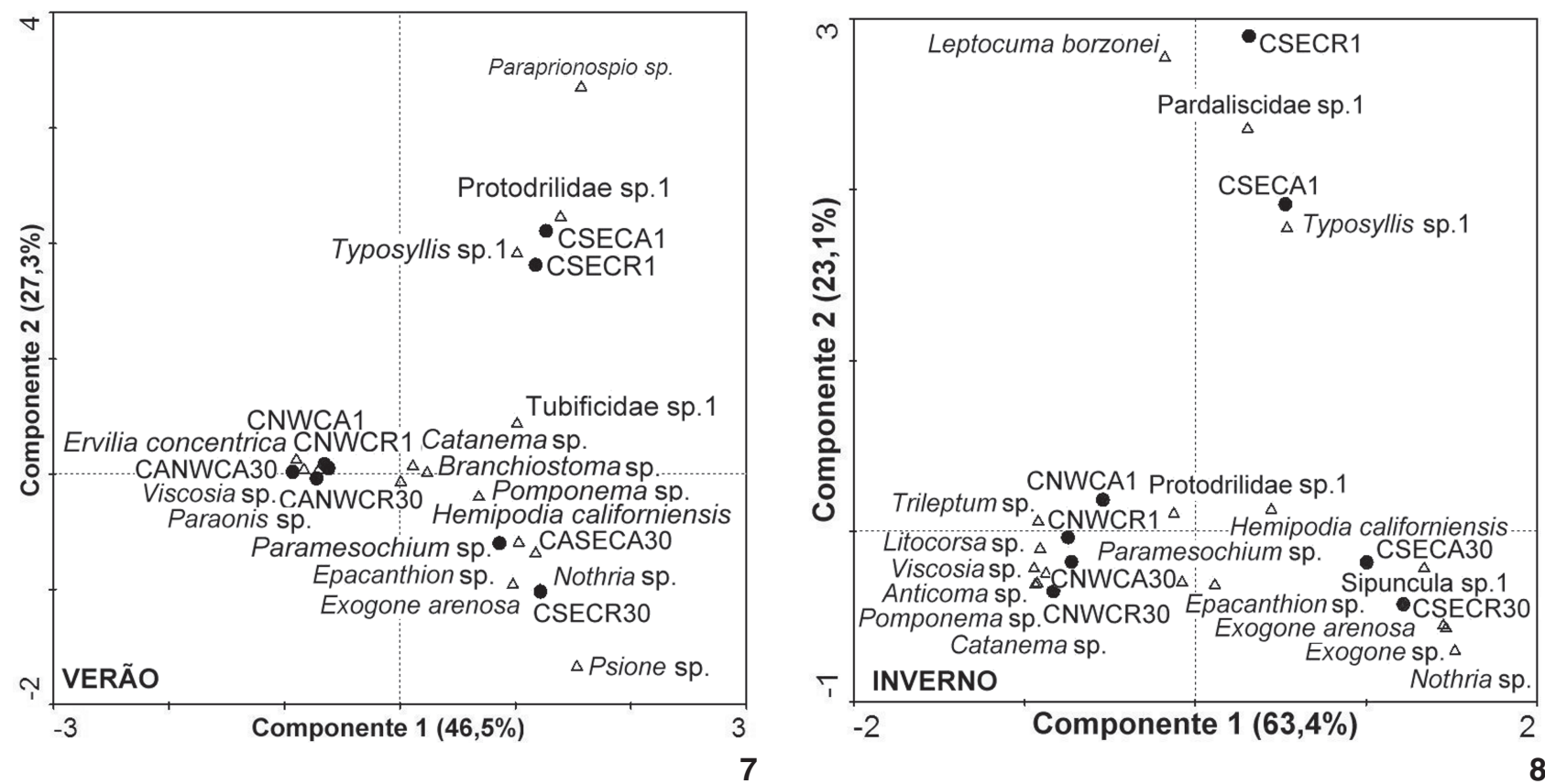

Figuras 7-8. Resultado da análise de Correspondência da infauna da llha Currais (C) no verão (7) e no inverno (8), nas faces exposta (SE) e protegida (NW); nas cristas (CR) e cavas (CA); nos distanciamentos de 1 e $30 \mathrm{~m}$. 

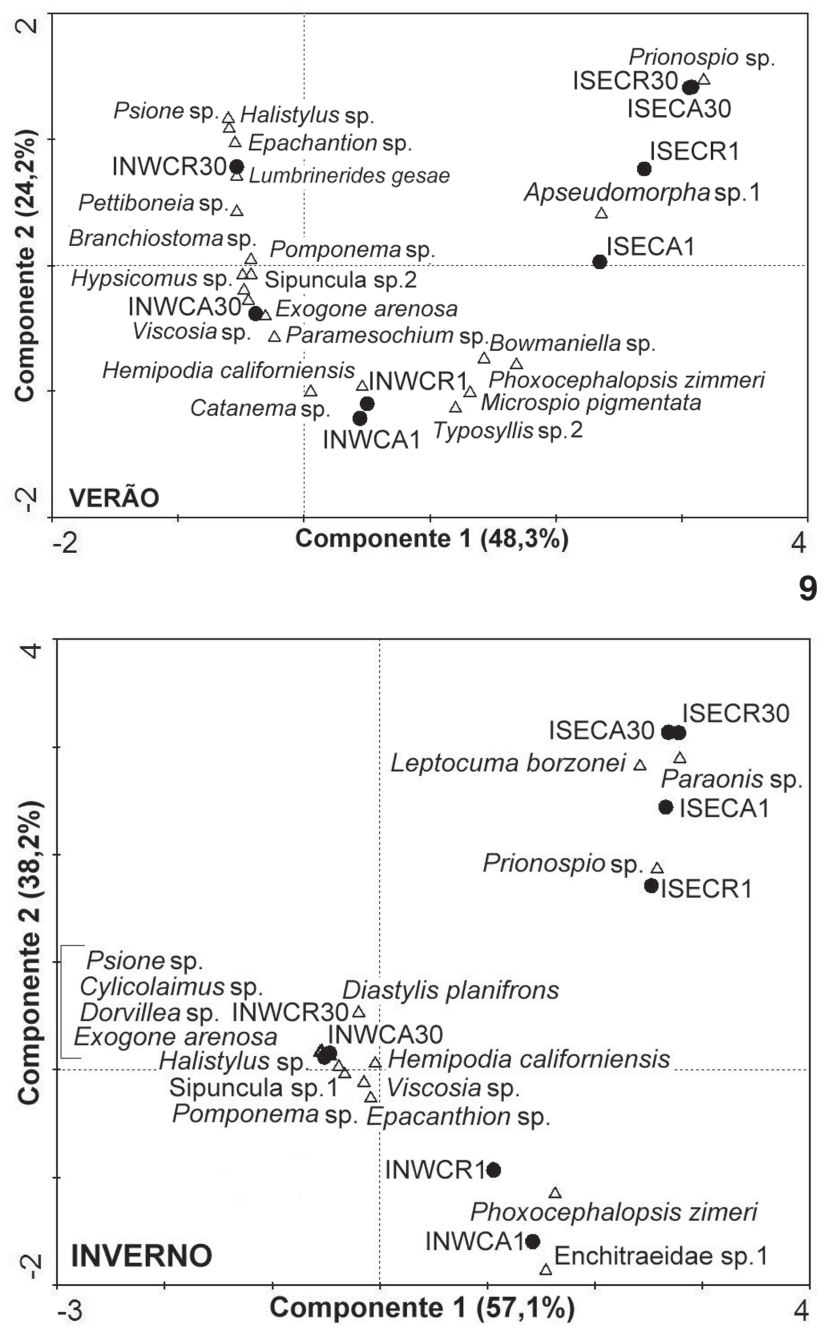

10

Figuras 9-10. Resultado da análise de Correspondência da infauna da laje submersa nas proximidades das ilhas Itacolomis (I) no verão (9) e no inverno (10), nas faces exposta (SE) e protegida (NW); nas cristas (CR) e cavas (CA); nos distanciamentos de 1 e $30 \mathrm{~m}$.

tegida das duas estruturas, com sedimentos mais grosseiros na face exposta da estrutura emersa e na protegida da estrutura submersa, indica que a interação da topografia com as correntes e ondas predominantes é bem diferente no caso de uma estrutura totalmente submersa. NetTo et al. (1999a) em um trabalho no Atol das Rocas, compararam a face exposta e a face protegida do atol, e encontraram areia grossa moderadamente selecionada na face exposta e areia média bem selecionada na face protegida. A ocorrência de grãos grosseiros nas áreas expostas foi atribuída à ação de correntes oceânicas e às ondas no local (NetTo et al. 1999b). Barros et al. (2001) em trabalhos com recifes em Botany Bay encontraram sedimentos compostos por

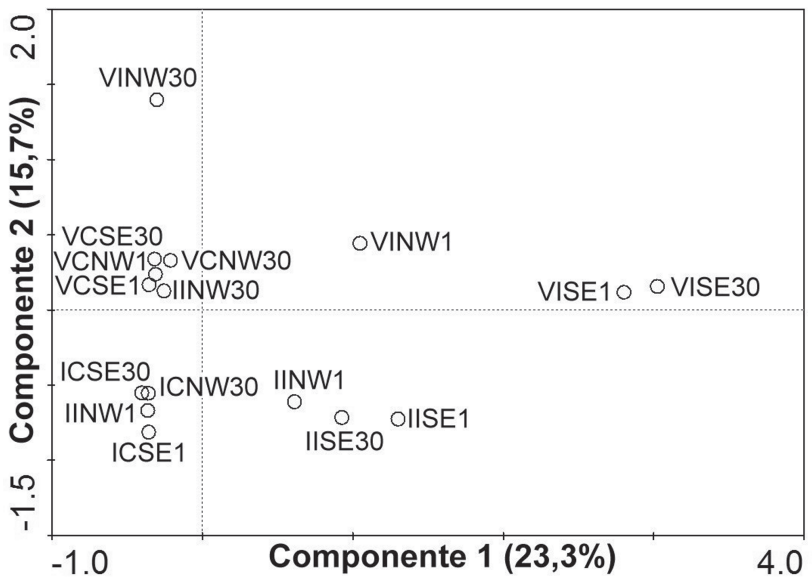

Figura 11. Resultado da análise de Correspondência da infauna nos pontos da llha Currais no verão (VC) e inverno (IC), e da laje submersa no verão (VI) e inverno (II) nas proximidades das ilhas Itacolomis nas faces exposta (SE) e protegida (NW); nos distanciamentos de 1 e $30 \mathrm{~m}$.

areia média com frações maiores de carbonato e em alguns casos encontraram frações mais grosseiras a um metro de algumas estruturas recifais. Entretanto, em locais mais afastados dos recifes, a maior parte dos sedimentos apresentou frações finas. De maneira geral, os padrões encontrados refletem as condições hidrodinâmicas prevalecentes no ambiente, sob a ação constante de correntes próximas ao fundo. $\mathrm{O}$ resultado da ação destas correntes parece ser diferente se tratando de uma estrutura emersa ou submersa. Na primeira, existiria uma maior ação de correntes geradas por ondas refletidas na estrutura, a qual atuaria com um quebra-mar na face exposta. Já na segunda, a estrutura poderia produzir a quebra das ondas pela diminuição da profundidade e uma maior dissipação da energia na face protegida da estrutura. Trabalhos mais aprofundados, com medição direta de ondas e correntes no fundo nas adjacências destas estruturas, podem ajudar na compreensão destes diferentes padrões.

Na composição da infauna, a dominância de Polychaeta e Nematoda no verão e inverno nas duas estruturas foi similar aos resultados encontrados por NetTo et al. (1999a) no Atol das Rocas, verdadeiras estruturas recifais, com Polychaeta dominando, seguido de Oligochaeta e Nematoda. BARros et al. (2001) também encontraram um padrão semelhante em sedimentos adjacentes a estruturas rochosas. Neтto et al. (1999a) identificaram a dominância de poliquetas oportunistas que vivem na superfície do sedimento e sugeriram que o macrobentos pode responder rapidamente à instabilidade física do ambiente.

As associações infaunais diferiram entre as faces e, em alguns casos, entre as distâncias do recife, mostrando uma forte relação com as características do sedimento. Na estrutura emersa de Currais ocorreram associações exclusivas da face pro- 
tegida, e na face exposta associações a um metro diferentes daquelas a $30 \mathrm{~m}$ da estrutura. Na laje submersa ocorreu o contrário, houve associações exclusivas da face exposta e na face protegida as associações a um metro foram distintas daquelas a $30 \mathrm{~m}$ da estrutura. NeтTo et al. (1999a) encontraram diferenças nas comunidades na comparação entre as faces, relacionadas com as características ambientais. BARros et al. (2001) encontraram maior variabilidade das associações próximas a recifes como resultado das modificações na distribuição do sedimento e na concentração de matéria orgânica através da presença da estrutura. Similarmente, no presente trabalho houve associações faunísticas determinadas pelas características físicas de sedimento e marcas de ondulação, as quais responderam pela sua vez à ação diferencial de agentes físicos, ondas e correntes, atuando e determinando as características do sedimento. A distribuição destas associações também poderia seguir a variabilidade da composição do sedimento em sublitoral. No entanto, estudos em fundos arenosos finos de plataforma sem a presença de estruturas recifais mostram uma grande homogeneidade nas associações bentônicas em distâncias variando de $50 \mathrm{~cm}$, 5 m, 50 m e 500 m (Kendal \& Widdicombe 1999).

Quando considerada uma menor escala espacial, como a determinada pelas marcas de ondulação, não foram verificadas no presente trabalho diferenças entre as associações da infauna das cristas e das cavas, tanto nas faces expostas como nas protegidas das estruturas. Num estudo relativamente recente onde as marcas de ondulação apresentaram maior tamanho e em geral estiveram mais próximas das estruturas rochosas, houve maiores abundâncias nas cavas do que nas cristas (BARros et al. 2004). Entretanto, o tamanho da infauna parece ser uma variável importante a ser considerada na percepção de variações na composição entre cristas e cavas, como apontado por LANGLois et al. (2006) num estudo em estruturas rochosas na ilha de Nova Zelândia.

A análise mostra que as comunidades da infauna que se desenvolvem nos substratos moles adjacentes a estruturas emersas e imersas diferem entre si. As maiores diferenças nas comunidades que se desenvolvem nos substratos adjacentes podem ser consideradas uma resposta às interações das ondas com a estrutura submersa, que nessa situação parecem ser mais intensas. Assim, deve ser enfatizado o caso da estrutura submersa, onde as ondas passam sobre a estrutura e aumentam a profundidade na face protegida, principalmente no inverno, onde o sedimento apresentou grãos de tamanho maior junto com as maiores marcas de ondulação.

De maneira geral, os padrões sedimentológicos e das associações da infauna refletiram as condições hidrológicas geradas pela interação da hidrografia local com a fisionomia das estruturas. Este parece ser um padrão geral tanto para estruturas rochosas como para verdadeiros recifes, mas outros estudos são necessários para identificar as relações entre forma e tamanho de estrutura e quais as respostas da infauna do substrato adjacente.

\section{AGRADECIMENTOS}

À Coordenação de Aperfeiçoamento de Pessoal de Nível Superior e ao Conselho Nacional de Desenvolvimento Científico e Tecnológico pela concessão das bolsas de doutorado.

\section{LITERATURA CITADA}

Angulo, R.J. \& A.D. AraúJo, 1996. Classificação da costa paranaense com base na sua dinâmica, como subsídio à ocupação da orla litorânea. Boletim Paranaense de Geociências 44: 7-17.

Baine, M. 2001. Artificial reefs: a review of their design, application, management and performance. Ocean \& Coastal Management 44: 241-259.

Barros, F.; A.J. Underwood \& M. Lindegarth. 2001. The influence of rocky reefs on structure of benthic macrofauna in nearby soft-sediments. Estuarine, Coastal and Shelf Science 52: 191-199.

Barros, F.; A.J. Underwood; \& P. Archambault. 2004. The influence of troughs and crests of ripple marks on the structure of subtidal benthic assemblages around rocky reefs. Estuarine, Coastal and Shelf Science 60 (4): 781-790.

Borzone, C.A.; P.R. Pezzuto \& E. Marone. 1999. Oceanographic characteristics of a multi-specific fishing ground of the Central South Brazil Bight. Marine Ecology 20 (2): 131-146.

Dean, W.E. 1974. Determination of carbonate and organic matter in calcareous sediments and sedimentary rocks by loss on ignition: comparison with other methods. Journal of Sedimentary Petrology 44: 242-248.

Galehouse, J.S. 1971. Sedimentation analysis, p. 69-94. In: R.E. CARVER (Ed.). Procedures in sedimentary petrology. New York, Wiley-Interscience, 653p.

GARRISON, T. 1996. Oceanography: an introduction to Marine Science. Wadsworth United States, Publishing Company, $2^{\text {nd }}$ ed., $574 \mathrm{p}$.

JAAP, W.C. 2000. Coral reef restoration. Ecological Engeneering 15: 345-364.

Kendal, M.A. \& S. Widdicombe. 1999. Small scale patterns in the structure of macrofaunal assemblages of shallow soft sediments. Journal of Experimental Marine Biology and Ecology 237: 127-140.

LANGLois, T.J.; M.J. ANDERSON \& R.C. BABCOCK. 2006. Inconsistent effects on different size classes of macrofauna in adjacent sand habitats. Journal of Experimental Marine Biology and Ecology 334: 269-282.

Legendre, P. \& L. Legendre. 1998. Numerical Ecology. Netherlands, Elsevier Science, 852p.

NetTo, S.A.; M.J. Atrill \& R.M. WARWick. 1999a. Sublittoral meiofauna of Rocas Atoll (NE Brazil): indirect evidence of a topographically controlled front. Marine Ecology Progress Series 179: 175-186.

Netto, S.A.; R.M. Warwick \& M.J. Atrill. 1999b. Meiobenthic and macrobenthic community structure in carbonate sediments of Rocas Atoll (North-east, Brazil). Estuarine, 
Coastal and Shelf Science 48: 39-50.

Noernberg, M.A.; E. Marone; R.J. Angulo. 2007. Coastal currents and sediment transport in Paranaguá estuary complex navigation channel. Boletim Paranaense de Geociências 60-61: 45-54.

Posey, M.H. \& W.G. Ambrose. 1994. Effects of proximity to an offshore hard-bottom reef on infaunal abundances. Marine Biology 118: 745-753.

Suguio, K. 1973. Introdução à sedimentologia. São Paulo,
Edgard Blücher, Editora da Universidade de São Paulo, 317p. Suguio, K. 1992. Dicionário de Geologia Marinha. São Paulo, Editora T.A. Queiroz, 171p.

TANNER, W.F. 1995. Environmental clastic granulometry. Tallahassee, Florida Geological Survey, Special Publication 40, 163p.

Wolanski, E. \& W.M. HAMmer. 1988. Topographically controlled fronts in the ocean and their biological influence. Science 241: $177-181$.

Submitted: 13.XII.2008; Accepted: 11.XII.2009.

Editorial responsibility: Paulo da Cunha Lana 